\title{
Failure Analysis of MEMS Using Thermally-Induced Voltage Alteration
}

\author{
Jeremy A. Walraven, Edward I. Cole Jr., and Paiboon Tangyunyong \\ Sandia National Laboratories, P.O. Box 5800, MS 1081, Albuquerque, NM 87185-1081, USA \\ email: jawalra@sandia.gov
}

\begin{abstract}
Electrical shorting in micro-electro-mechanical systems (MEMS) is a significant production and manufacturing concern. We present a new approach to localizing shorted MEMS devices using Thermally-Induced Voltage Alteration (TIVA) [1]. In TIVA, the shorted, thermally isolated MEMS device is very sensitive to thermal stimulus. The site of the MEMS short will respond as a thermocouple when heated. By monitoring the potential across the shorted MEMS device as a laser scans across the sample, an image showing the location of the thermocouple (short site) can be generated. The TIVA signal for thermally isolated MEMS devices is much higher than that observed for conventional IC interconnections. This results from the larger temperature gradients generated during laser scanning due to little or no substrate heat sinking. The capability to quickly localize shorted MEMS structures is demonstrated by several examples. Thermal modeling of heat distributions is presented and is consistent with the experimental results.
\end{abstract}

\section{Introduction}

MEMS devices are important elements in sensor and communication devices, with new applications appearing continually. Electrical short circuiting of MEMS devices is a significant production and manufacturing concern. As with most technologies, the probability of yield and reliability problems increases as MEMS devices get smaller and more complex. Most electrically active components of MEMS devices are suspended above a ground plane or other electrically active/grounding regions. The most likely cause for short-circuit defects in MEMS can be attributed to stiction [2] or particle contamination [3]. Recent work has also shown the susceptibility of MEMS devices to ESD/EOS damage [4]. Although electrical short circuiting is a major concern, no techniques are currently available to characterize MEMS devices quickly and noninvasively. Current methods for characterizing electrical shorting in MEMS devices consist of electrical probing/testing, to verify the actuator (drive signal applied to the actuator) is short circuited, and scanning electron microscopy (SEM) or optical microscopy, to structurally characterize and localize the electrically shorted component. Electrical probing/testing can potentially damage the device, and most high-resolution SEM characterization applies a high-energy electron beam to the MEMS structure. This may damage any electronics in the vicinity of the MEMS device. The combination of structural and electrical characterization using SEM and electrical probing has proven to be both arduous and time consuming, often taking hours to localize the failure site.

We have found that the recently developed TIVA technique can be used to quickly localize shorted elements of MEMS devices. Through the use of TIVA, we have both electrically verified and physically localized the failed region of MEMS devices quickly, effectively, and efficiently. The paper will review the physics of TIVA and describe the analysis of defective MEMS devices. The paper will also show detailed thermal modeling and simulation results of heat dissipation in the thermally isolated MEMS structures.

\section{Physics of TIVA Imaging}

TIVA [1] for IC examination employs the constantcurrent biasing method used in Charge-Induced Voltage Alteration (CIVA) [5] and Light-Induced Voltage Alteration (LIVA) [6]. The constant-current biasing approach provides an extremely sensitive method for detection of subtle changes in the IC or MEMS power demand. In TTVA, localized heating changes the resistance of a short, and the effects of this resistance change on the power demands of the entire IC are used to produce an image. Power consumption of a short will depend upon the resistance of the short and its location in the IC. For example, a $V_{D D}$ to $V_{S S}$ short may dissipate more power than a short between two signal lines. If the short is of a metallic nature, the increase in temperature will increase the resistance of the short, thereby reducing the power demands of the IC. The change in resistance of a short with heating from the scanned laser can be expressed by Eq. 1 [7]:

$$
\rho=\rho_{0}\left(1+\alpha\left(T-T_{0}\right)\right)
$$




\section{DISCLAIMER}

This report was prepared as an account of work sponsored by an agency of the United States Government. Neither the United States Government nor any agency thereof, nor any of their employees, make any warranty, express or implied, or assumes any legal liability or responsibility for the accuracy, completeness, or usefulness of any information, apparatus, product, or process disciosed, or represents that its use would not infringe privately owned rights. Reference herein to any specific commercial product, process, or service by trade name, trademark, manufacturer, or otherwise does not necessarily constitute or imply its endorsement, recommendation, or favoring by the United States Government or any agency thereof. The views and opinions of authors expressed herein do not necessarily state or reflect those of the United States Government or any agency thereof. 


\section{DISCLAIMER}

Portions of this document may be illegible in electronic image products. Images are produced from the best available original document. 
where $\rho$ is the resistivity, $\rho_{0}$ is the resistivity at $T_{0}$, $\alpha$ is the temperature coefficient of resistivity, $T$ is the temperature, and $T_{0}$ is the reference temperature.

When localizing shorts in signal lines, the IC must be biased (statically) with sufficient potential to "activate" the short. For a 3-V IC, the constant current should be elevated to achieve a voltage of 2.5 to $3 \mathrm{~V}$. The thermally-induced resistance changes will alter the voltage of transistor gates driven by the shorted conductors, producing the same amplification effects seen in CIVA.

If the short is between power buses, then only a minimal current $(100 \mu \mathrm{A}$ to $1 \mathrm{~mA})$ is required through the short while imaging. The voltage obtained may be well below the normal operating potential. Under these conditions, there is no CIVAlike amplification by transistor gates, but neither is there any background power consumption due to biasing the entire IC that can mask weaker signals. The resulting sensitivity in detecting shorts is generally better for power-bus cases than signal lines, but specific cases vary in sensitivity. For some shorts, no applied current is necessary because the heated short produces its own bias via a thermocouple effect. Certainly the setup is much easier for "hard" shorts where no bias is applied. Also, because no bias is applied the risk of further damage through biasing is circumvented. Fig. 1 is a TIVA example localizing a short on the front side of an IC.

The resistance change with localized heating in TIVA is the basis of the optical-beam induced resistance change (OBIRCH) technique [8]. For OBIRCH, the change in IC power consumption is detected by an IC current change with constant-voltage biasing, yielding limited detection sensitivity. The constantcurrent biasing approach used in TIVA produces greater sensitivity in localizing shorts. OBIRCH using constant-current biasing was mentioned in a recent review article [9], which also indicated the improved sensitivity seen with the "IVA" techniques.

Application of TIVA to MEMS presents some special opportunities. Because some MEMS structures are thermally isolated from the substrate of the MEMS device, the structures can be easily heated with much lower power than when TIVA is applied to ICs. In fact, some devices require care to avoid overheating and possible damage to the MEMS structure by high temperature alteration of the thermally isolated components. Additionally, a number of MEMS devices do not have active IC structures, i.e., Si diffusions. With these structures there is no concern of photocurrent effects swamping out the TIVA signals. Therefore, shorter-wavelength lasers with better spatial resolution can be used for TIVA
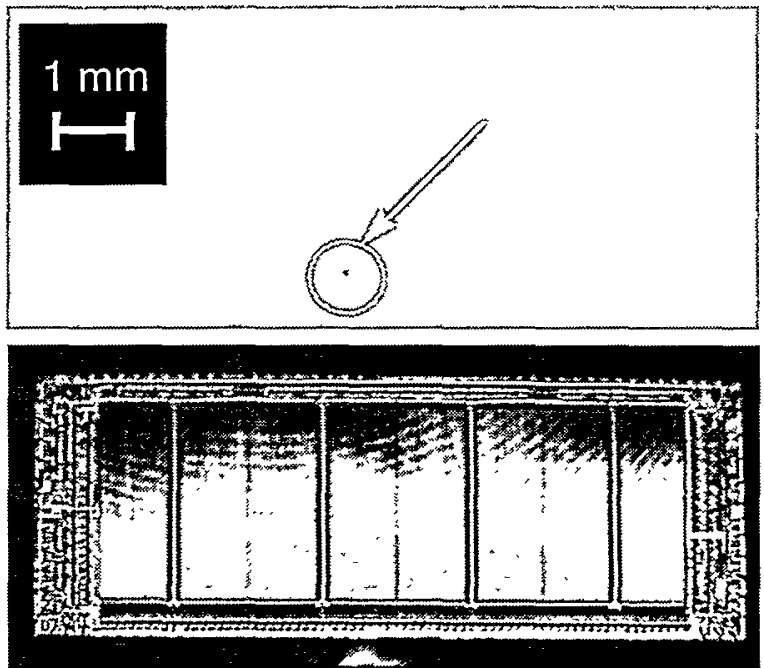

Fig. 1. Front side TIVA example showing the location of a short. A reflected light image of the same freld of view is shown for registration.

images. The improved spatial resolution can also be seen in the reflected light images used for registration.

\section{Sandia MEMS Microengine}

The Sandia-fabricated microengine was used as the test vehicle for assessing the effects of a short-circuit event. Illustrated in Fig. 2 is an optical micrograph of the Sandia surface-micromachined polysilicon microengine accompanied by SEM micrographs of the gear and comb-drive actuators respectively. The Sandia microengine consists of orthogonal linear comb drive actuators mechanically connected to a rotating gear. By applying the appropriate drive signals (voltages), linear displacements of the comb drives are transformed into rotary motion. The $\mathrm{X}$ and $Y$ linkage arms are connected to the gear by a pin joint. The gear rotates around a hub, which is anchored to the substrate. Fig. 3 shows the packaged part consisting of one die with four microengines (2 actuators per microengine). Each microengine is driven by $\mathrm{X}$ and $\mathrm{Y}$ electrostatic actuators. Each actuator utilizes two drive signals (either up/down or left/right depending upon the orientation of the microengine). These actuators consist of discrete levels of polysilicon to make a two-level comb finger structure. The comb fingers measure $48 \mu \mathrm{m}$ long and $2 \mu \mathrm{m}$ wide with a $2-\mu \mathrm{m}$ space between adjacent comb fingers and between the comb fingers and the ground plane. Figs. $4 a$ and $b$ illustrate the fixed and moveable comb-finger geometries from top and side perspectives.

PECEIVED

OCT 042000 


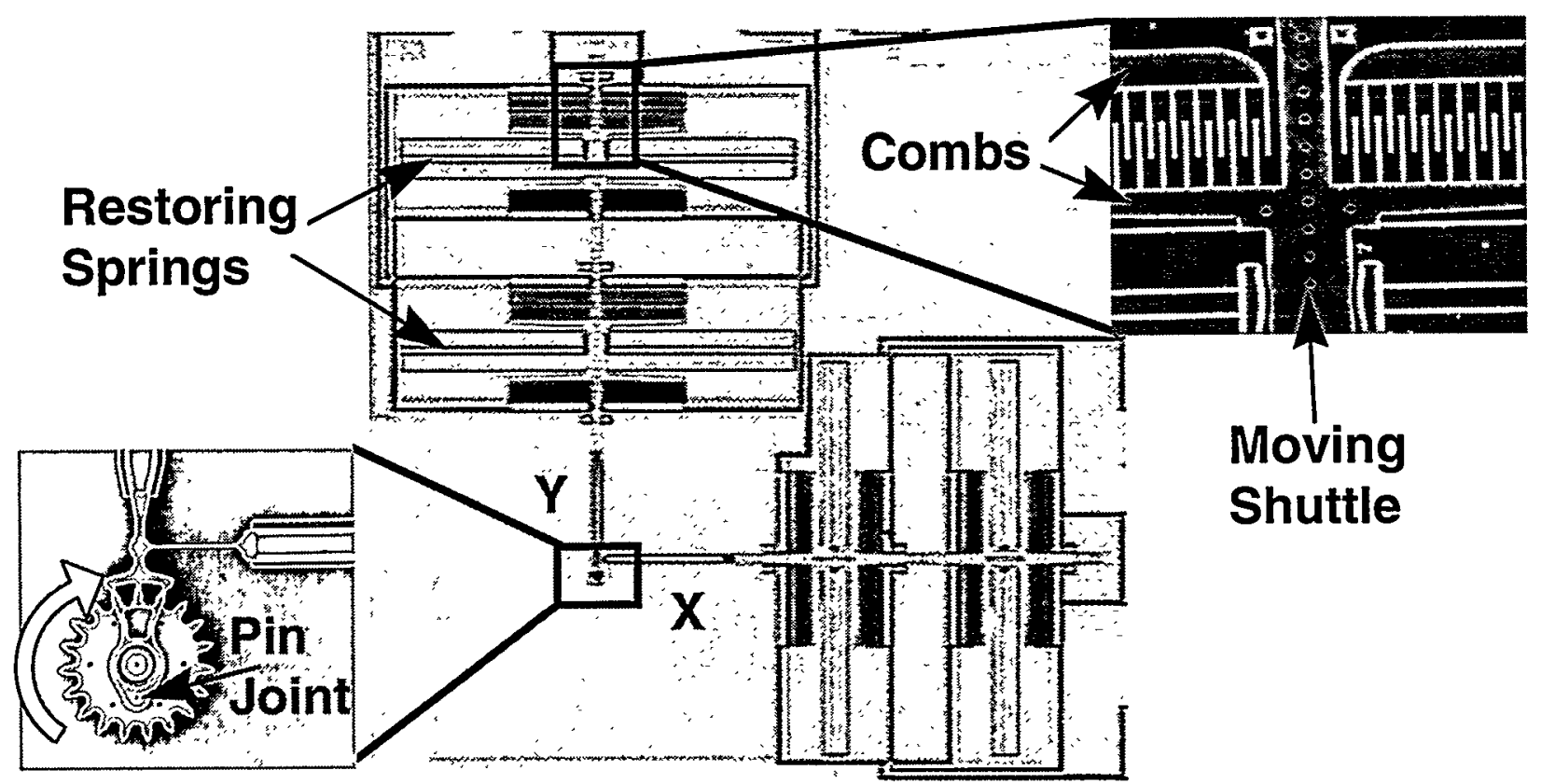

Fig. 2. Sandia microengine with expanded views of the $Y$ comb drive actuator (top right) and the rotating gear (bottom left). The white arrow indicates the direction of gear rotation.

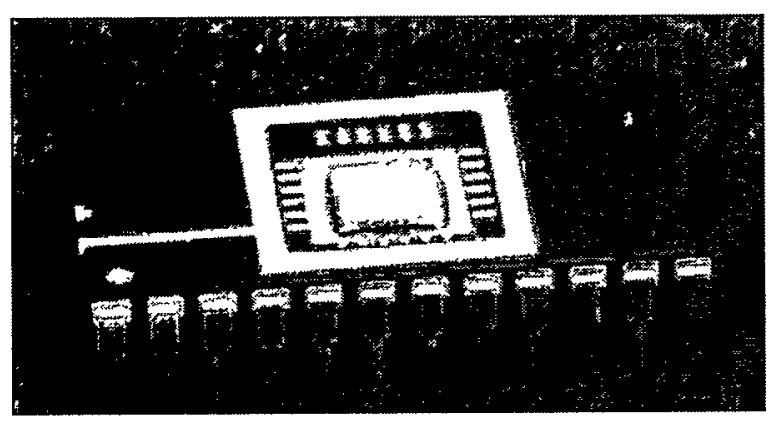

Fig. 3. 24-pin dual-in-line package (DIP) containing 4 electrostatically driven microengines (a total of 8 actuators, 16 drive signals).

\section{Thermal Modeling}

Thermal modeling and simulation were performed to understand the heating effects of a focused laser beam on the MEMS structures. A thermal modeling system produced by Harvard Thermal Inc. was used to evaluate the effects of laser irradiation of structurally isolated polysilicon [10]. In modeling, the silicon die was assumed to be $600 \mu \mathrm{m}$ thick. On top of the silicon substrate is a $0.6-\mu \mathrm{m}$-thick silicon dioxide $\left(\mathrm{SiO}_{2}\right)$ layer. A $0.8-\mu \mathrm{m}$-thick silicon nitride layer overlays the $\mathrm{SiO}_{2}$ layer. On top of this silicon nitride layer is a layer of $0.3-\mu \mathrm{m}$-thick polysilicon. This thin polysilicon layer (sheet resistance $=$ $40 \Omega /$ square) is normally referred to as the poly0 layer. There is another $1-\mu \mathrm{m}$-thick polysilicon layer on top of poly0 layer. This layer, normally known as poly 1 , has a sheet resistance of $22 \Omega /$ square. The
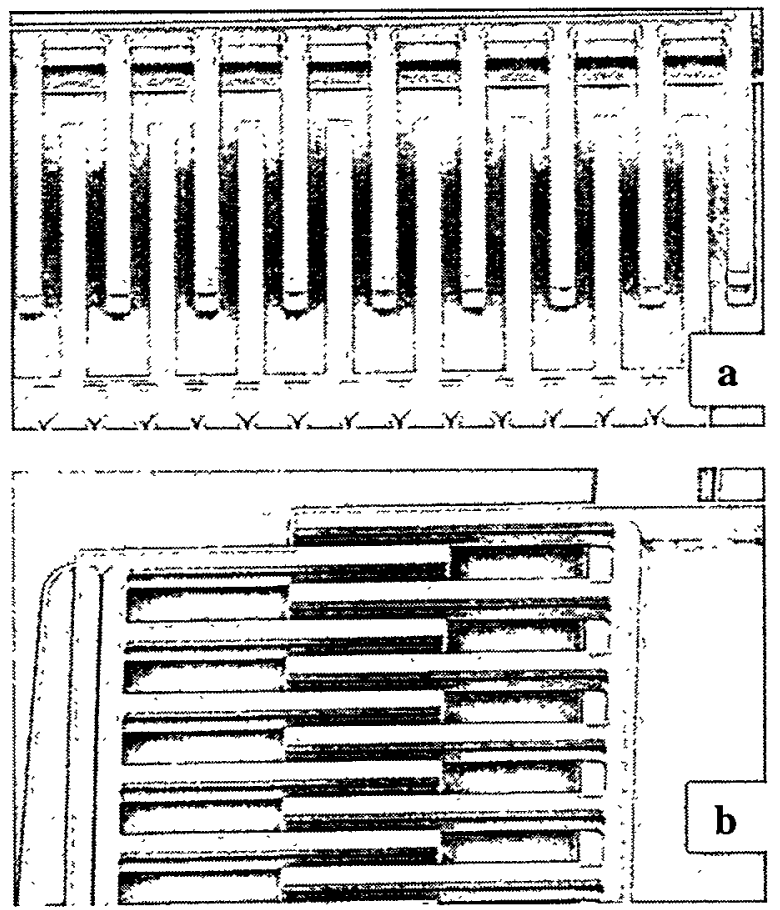

Figs. $4 \mathrm{a}$ and $\mathrm{b}$. (a) Front and (b) side views ( $40^{\circ}$ tilt) of a micromachine comb drive actuator.

comb fingers and shuttles are located in this layer. An air gap of $2 \mu \mathrm{m}$ separates the poly0 and poly 1 layers. The comb finger was assumed to be $2 \mu \mathrm{m}$ wide and $48 \mu \mathrm{m}$ long. Adjacent comb fingers are separated by a $2-\mu \mathrm{m}$-wide air gap. 
The laser spot size was assumed to be $2 \times 2 \mu \mathrm{m}(5 \mathrm{X}$ objective approximation). For a laser power of 140 $\mathrm{mW}$, the total focused laser power on the sample was measured to be approximately $16 \mathrm{~mW}$ on the sample surface. The laser absorption for the air gap, silicon nitride layer, silicon dioxide layer, and silicon substrate was assumed to be negligible. Laser absorption occurs primarily in the poly 0 and poly 1 layers. The absorption coefficients of the poly 0 and poly1 layers were found to be 735 and $336 \mathrm{~cm}^{-1}$ respectively based on an earlier calibration curve [11].

Fig. 5 shows the temperature profiles of the poly $0 / \mathrm{SiO}_{2} / \mathrm{SiN} / \mathrm{Si}$ substrate. In the simulation, it was assumed that $352 \mu \mathrm{W}$ of laser power was absorbed by the poly0 in a $2 \times 2 \mu \mathrm{m}$ area. The absorbed power was calculated based on the absorption coefficient of $735 \mathrm{~cm}^{-1}$ for the focused laser power of $16 \mathrm{~mW}$. Fig. 5 clearly shows that there is minimal temperature rise in the substrate. The maximum temperature rise is about $2{ }^{\circ} \mathrm{C}$ for a base temperature of $25^{\circ} \mathrm{C}$. The small rise in temperature can be attributed to rapid heat dissipation through the silicon substrate.

Fig. 6 shows the temperature profiles of the poly1 comb fingers on top of the poly0/SiO $/ 2 / \mathrm{SiN} / \mathrm{Si}$ substrate. The total absorption in a $2 \times 2 \mu \mathrm{m}$ area in one of the comb finger was calculated to be $528 \mu \mathrm{W}$.

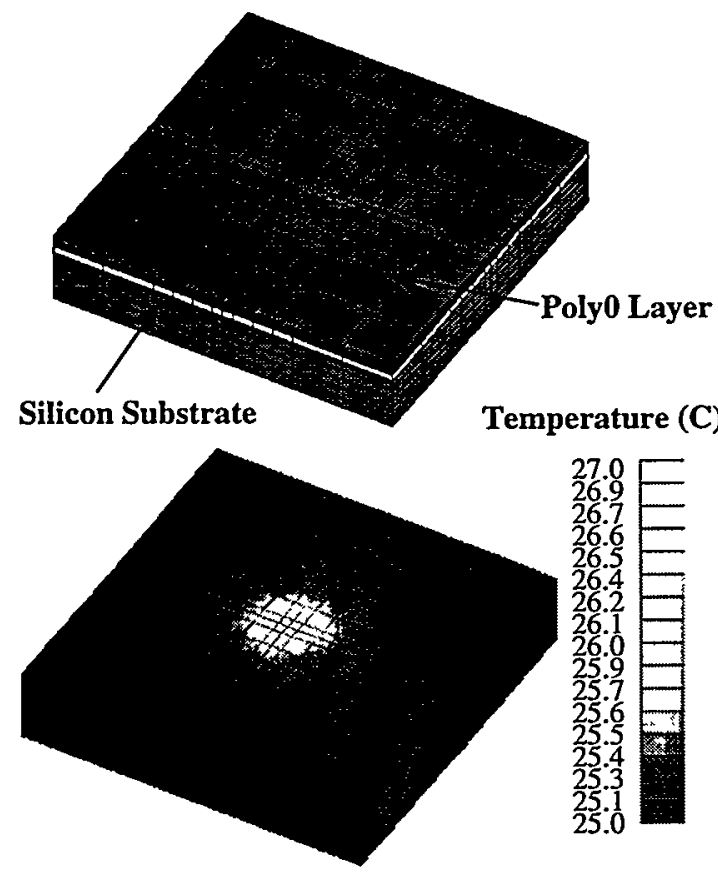

Fig. 5. The lattice structure (top) used in the simulation of temperature profiles of poly $0 / \mathrm{SiO}_{2} / \mathrm{SiN} / \mathrm{Si}$ substrate. The lattice structure shown is $34 \mu \mathrm{m}$ wide, $34 \mu \mathrm{m}$ long and $6.8 \mu \mathrm{m}$ thick. Calculated temperature profile (bottom) for the absorbed power of $352 \mu \mathrm{W}$ in a $2 \times 2 \times 0.3 \mu \mathrm{m}$ volume in the poly0 layer.
The modeling also included the laser absorption in the poly0 layer of $352 \mu \mathrm{W}$. The modeling shows that there is a significant temperature rise of around $40^{\circ} \mathrm{C}$ above the base temperature of $25^{\circ} \mathrm{C}$. The air gap between poly 0 and poly 1 layers acts as a good thermal insulator and prevents rapid heat dissipation through the silicon. The air gap between adjacent comb fingers also prevents the dissipation through adjacent fingers. Most of the heat dissipated quickly along the length of the comb finger.

In Fig. 7 , the simulation assumes a particle short between the poly 0 and poly 1 layers. The particle producing the short is assumed to be $2 \times 2 \times 2 \mu \mathrm{m}$ in size and to be made up of polysilicon. The absorption coefficient of this particle was assumed to be the same as the polyl layer. Even with the particle short, the thermal profile in Fig. 7 looks very similar to that of Fig. 6 . The air gap between poly0 and poly 1 and between adjacent comb fingers still dominates the heat dissipation and thermal distribution. The peak temperature rise in this case is about $42^{\circ} \mathrm{C}$ above the base temperature of $25^{\circ} \mathrm{C}$.

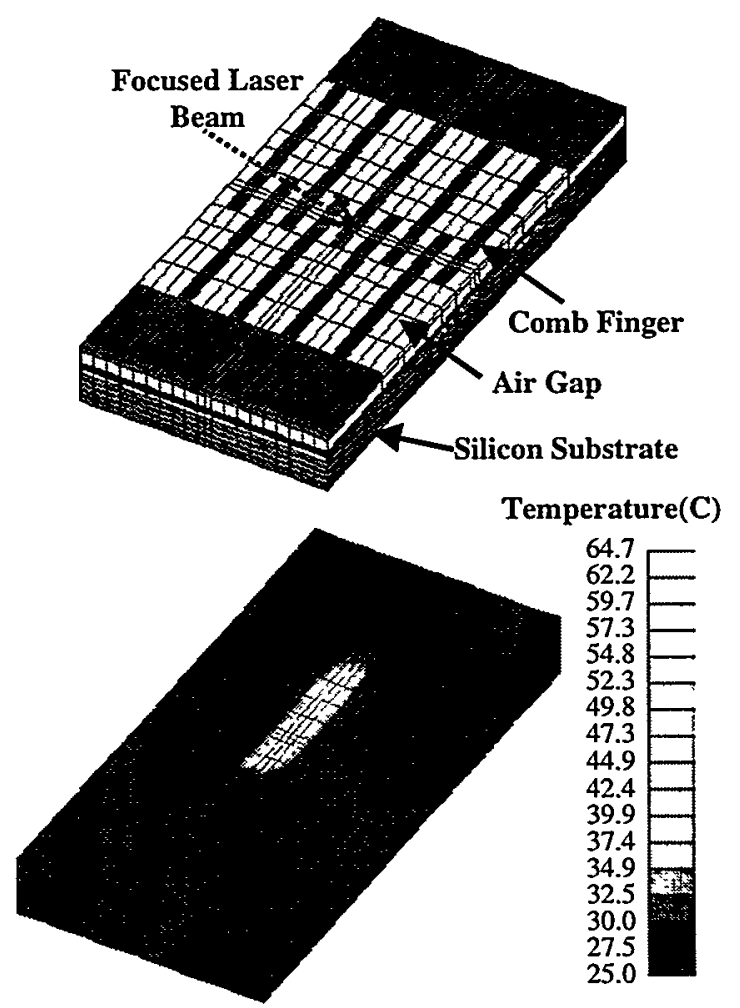

Fig. 6. The lattice structure (top) used in the simulation of temperature profiles of poly1 on poly0/SiO $/ 2 / \mathrm{SiN} / \mathrm{Si}$ substrate. The lattice structure shown is $38 \mu \mathrm{m}$ wide, $80 \mu \mathrm{m}$ long and $9.8 \mu \mathrm{m}$ thick. Calculated temperature profile (bottom) for the absorbed power of $528 \mu \mathrm{W}$ in a $2 \times 2 \times 1 \mu \mathrm{m}$ volume in the poly1 layer and $352 \mu \mathrm{w}$ in a $2 \times 2 \times 0.3 \mu \mathrm{m}$ volume in poly0 layer. 

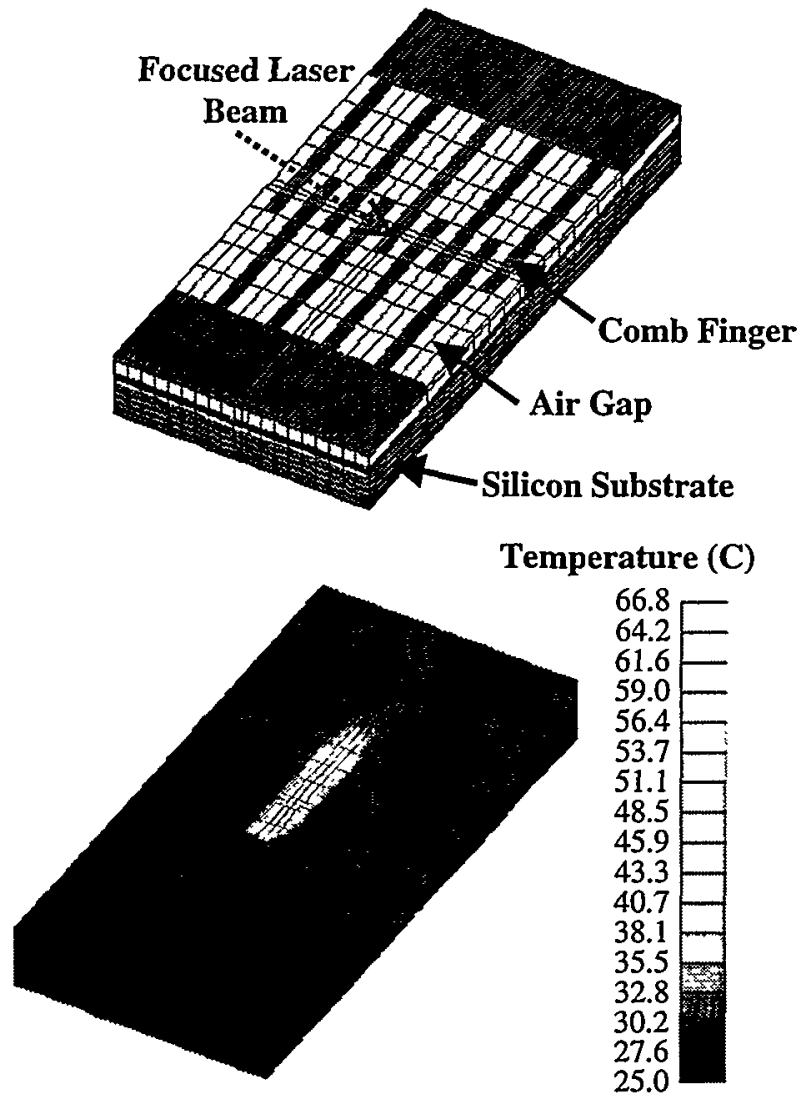

Temperature (C)

$66.8 \square$
$64.2 \square$
61.6
59.0
56.4
53.7
51.1
48.5
45.9
43.3
40.7
38.1
35.5
32.8
30.2
27.6
25.0

Fig. 7. The lattice structure (top) used in the simulation of temperature profiles of poly1 on poly0/SiO $/ 2 / \mathrm{SiN} / \mathrm{Si}$ substrate. The lattice structure shown is $38 \mu \mathrm{m}$ wide, $80 \mu \mathrm{m}$ long and $9.8 \mu \mathrm{m}$ thick. There is particle short between poly0 and poly 1 . The particle was assumed to be made of polysilicon and 2 $\times 2 \times 2 \mu \mathrm{m}$. Calculated temperature profile (bottom) for the absorbed power of $528 \mu \mathrm{W}$ in a $2 \times 2 \times 1 \mu \mathrm{m}$ volume in the poly 1 layer and $352 \mu \mathrm{w}$ in a of $2 \times 2 \times$ $0.3 \mu \mathrm{m}$ volume of poly0 layer. The absorbed power in the particle was assumed to be $1.04 \mathrm{~mW}$.

Fig. 8 shows the simulation where there is a particle short between two adjacent comb fingers with $16 \mathrm{~mW}$ of laser power focused on one of the fingers. The particle was assumed to be made up of polysilicon with a size of $2 \times 2 \times 1 \mu \mathrm{m}$. The air gap between poly0 and poly 1 still prevents any significant heat dissipation through the substrate. Most of the heat dissipation not only occurs along the comb finger where the laser is focused, but also along the adjacent shorted finger. There are two paths for heat to dissipate, resulting in a lower peak temperature rise of $21{ }^{\circ} \mathrm{C}$. This peak temperature rise is roughly half the values of those found in Figs. 6 and 7 , but still very large compared to nonthermally insulated structures.

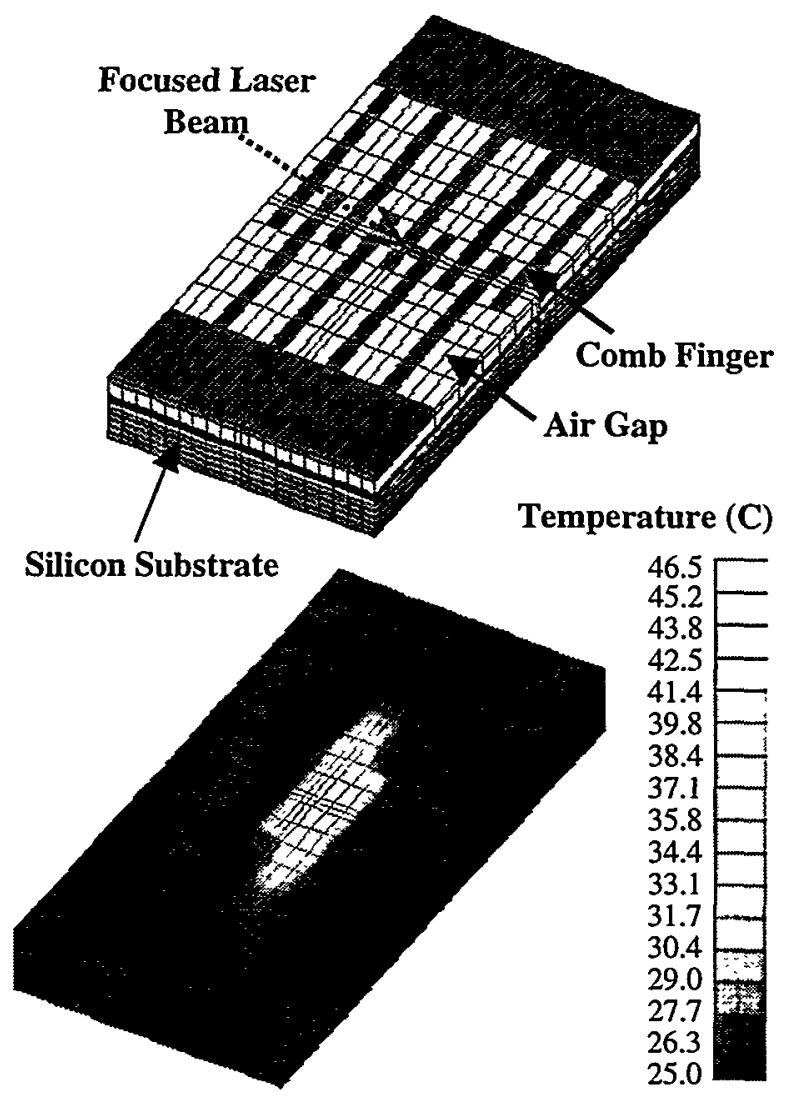

Fig. 8. The lattice structure (top) used in the simulation of temperature profiles of polyl on polyO/SiO $/ 2 / \mathrm{SiN} / \mathrm{Si}$ substrate. The lattice structure shown is $38 \mu \mathrm{m}$ wide, $80 \mu \mathrm{m}$ long and $9.8 \mu \mathrm{m}$ thick. There is a particle short between two adjacent comb fingers. The particle was assumed to be made of polysilicon and $2 \times 2 \times 1 \mu \mathrm{m}$. Calculated temperature profile (bottom) for the absorbed power of $528 \mu \mathrm{W}$ in a $2 \times 2 \times 1 \mu \mathrm{m}$ volume in one of the shorted comb finger and $352 \mu \mathrm{W}$ in $\mathrm{a} 2 \times 2 \times 0.3 \mu \mathrm{m}$ volume in poly0 layer.

\section{Results}

Three different failure types are described to demonstrate the usefulness of the TIVA technique in localizing shorted MEMS devices. No bias was applied to any of the MEMS devices displayed, avoiding any altering of the failure site by joule heating.

Fig. 9 displays a low magnification TIVA image of a shorted device along with a reflected light image of the same field of view. The TIVA site is highlighted with an arrow. Fig. 10 is a higher magnification image of the site from Fig. 9 showing a MEMS comb finger shorted to the ground plane beneath the comb fingers. The focused ion beam (FIB) was used to excise the moveable shuttle from the device to aid in 

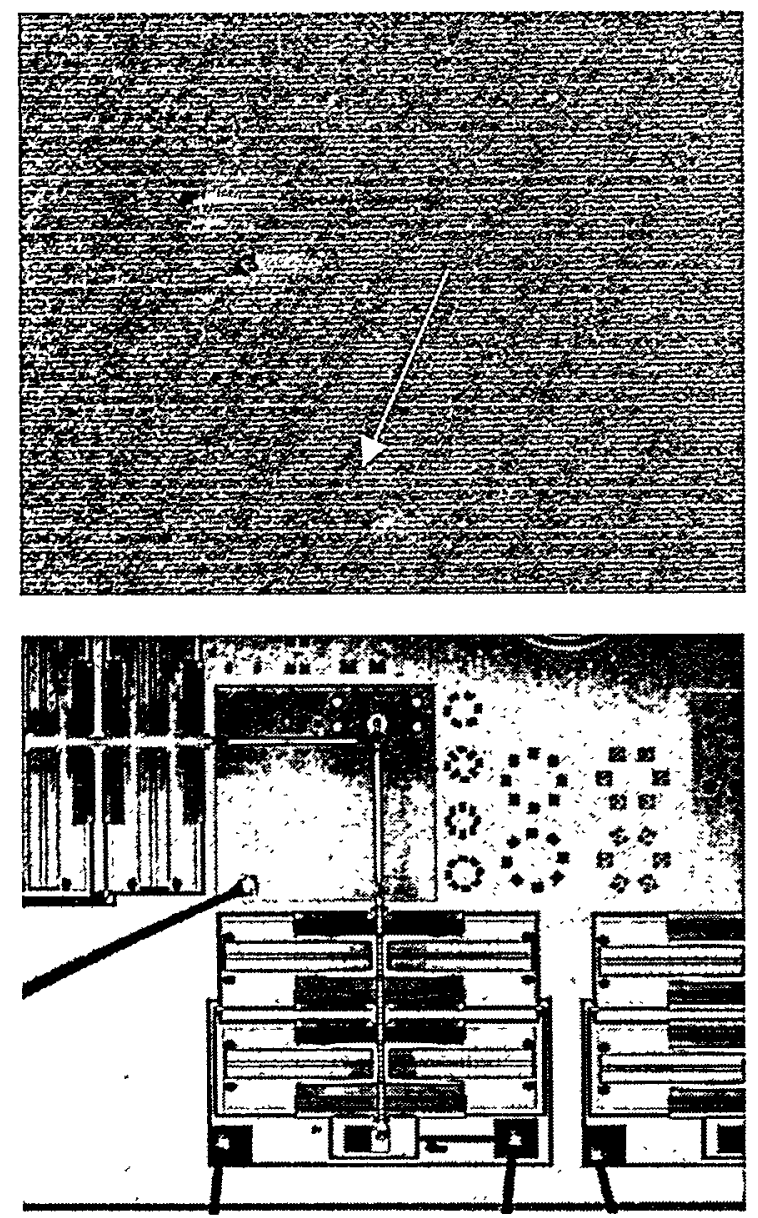

Figs. 9a and b. TIVA (a-top) and reflected-light (bbottom) images and a short defect on a MEMS device. The field of view is the same for both images.

characterizing the shorted comb finger. Standard TIVA imaging of ICs uses a $435-\mathrm{mW}, 1.3-\mu \mathrm{m}$ laser. Because the MEMs sample has no active photocurrent generation sites and is thermally isolated from the substrate, a $5-\mathrm{mW}, 543-\mathrm{nm}$ laser is used for the images in Fig. 9. This laser is used for all the TIVA imaging of MEMS devices shown. The shorter wavelength produces superior spatial resolution permitting relatively easy defect identification. Subsequent SEM analysis of the shorted comb finger is shown in Fig. 11. Here, the short is the result of contact between a lower level (poly1) comb finger to the ground plane (poly0).

A second TIVA example is shown in Figs. 12 and 13. Fig. 12 is a low-magnification view, and Fig. 13 shows the defect at higher magnification. Here the lower, moveable comb finger (bright contrast) of a stacked MEMS structure has laterally shorted to the neighboring finger. Note that the entire uncovered portion of the comb finger shows up in the TIVA image, as predicted by the thermal modeling. The
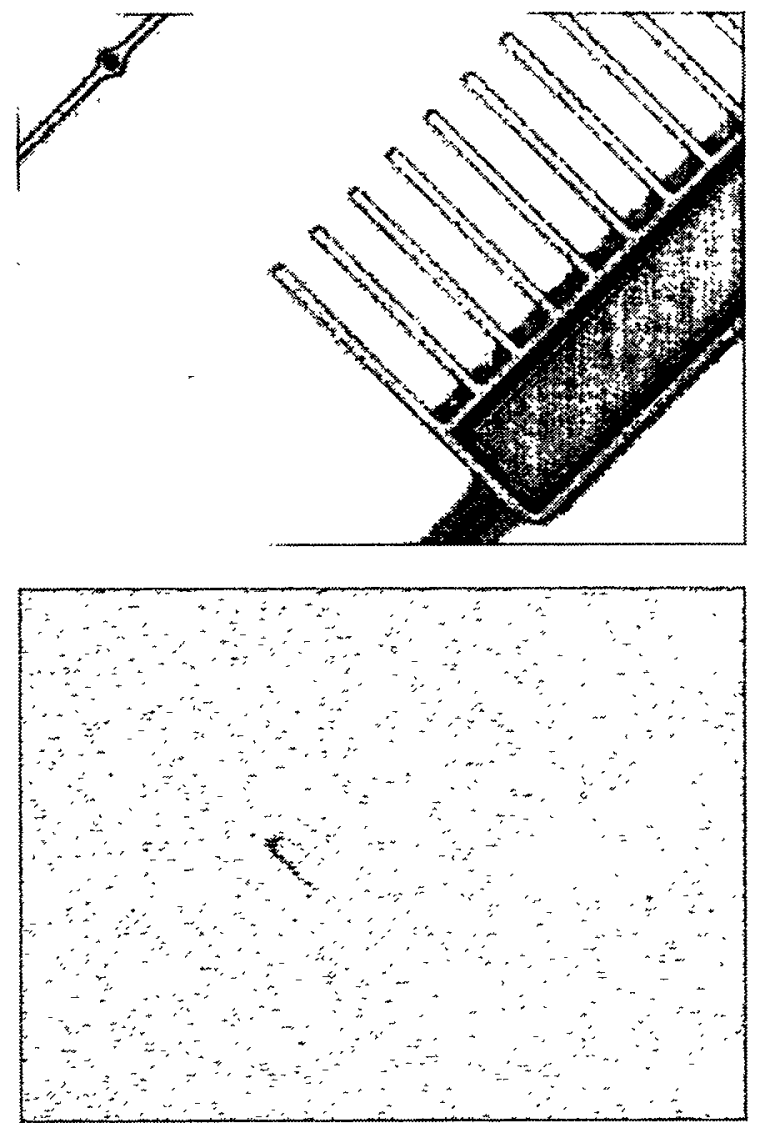

Figs. 10a and b. (a) Reflected-light and (b) TIVA image using a 5-mW, 540-nm laser. A bottom level comb finger shorting to the ground plane has been identified.

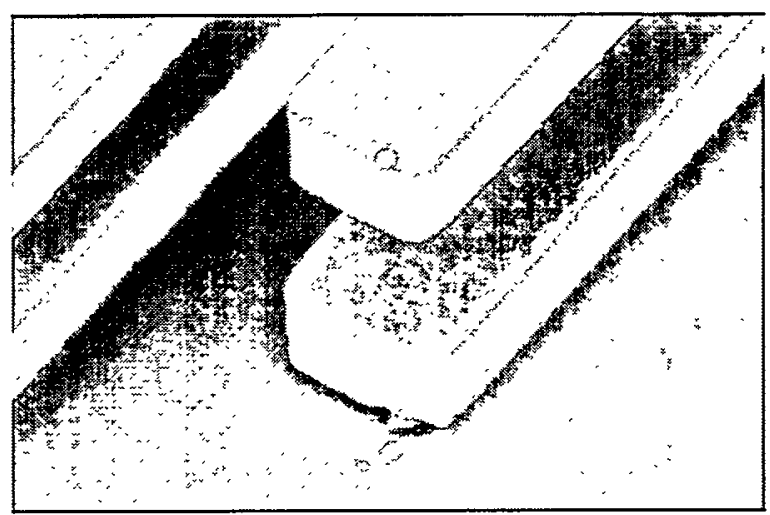

Fig. 11. SEM micrograph of an electrostatic comb finger shorted to the ground plane.

fixed finger to the right has a weak, dark TIVA contrast that is difficult to see at the edge of the brighter, moveable comb.

Figs. 14 and 15 show a particle short example between two comb fingers at low and high magnification. Unlike Fig. 13, the separation between the fingers allows the bright/dark contrast to 

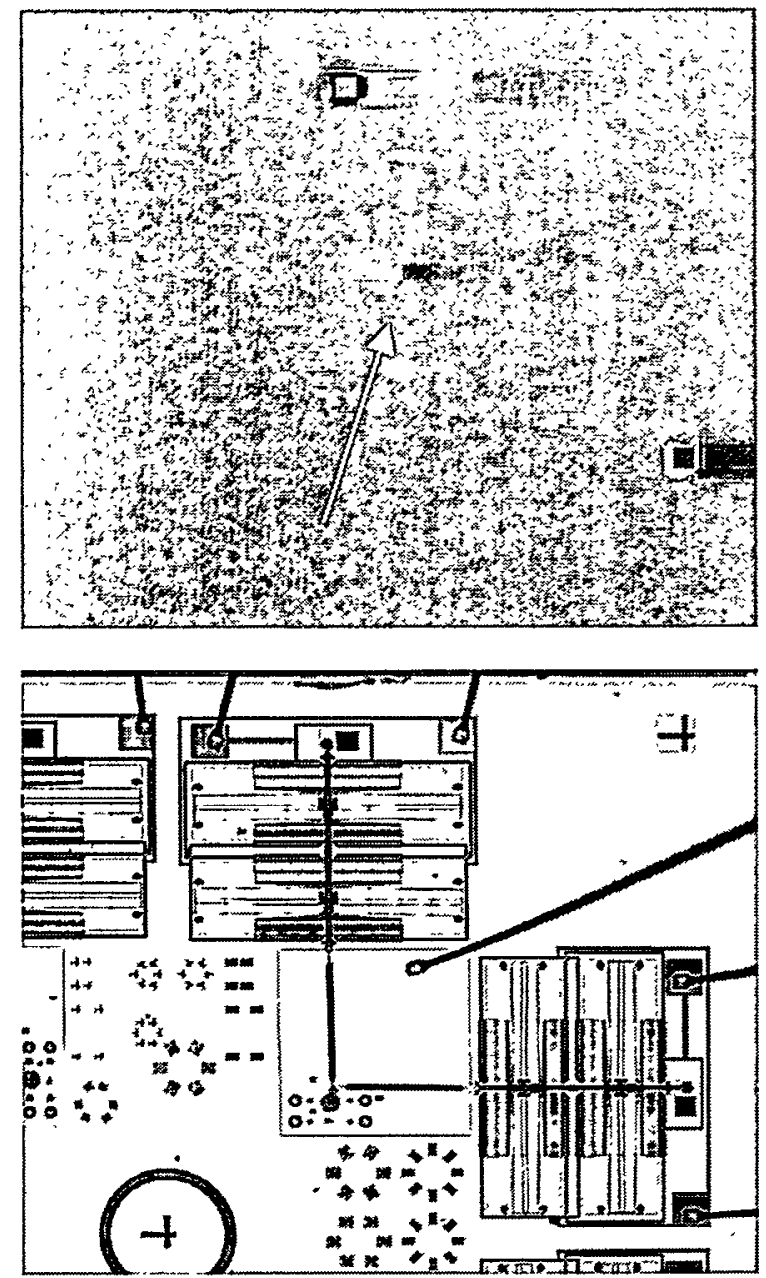

Figs. 12a and $b$. Low-magnification TIVA (a-top) and reflected-light (b-bottom) images and a lateral short defect on a MEMS device. The field of view is the same for both images.

be easily seen. The change in contrast (voltage) polarity is produced by the thermocouple effect as either side of the short is heated. As with the other two TIVA examples, the failure site is easily identified.

\section{Conclusions}

MEMS devices are playing an increasingly key role in sensor and optical communication electronics. Electrical shorts in MEMS structures are major reliability concerns for these devices because of the intrusive nature of most techniques and the time requirèd for defect localization. TIVA has been demonstrated to be an effective tool for rapidly and non-invasively localizing shorts on MEMS devices. As predicted by thermal modeling and demonstrated in the failure examples, the thermal isolation of moveable MEMS structures permits the use of far lower laser power for heating when compared to
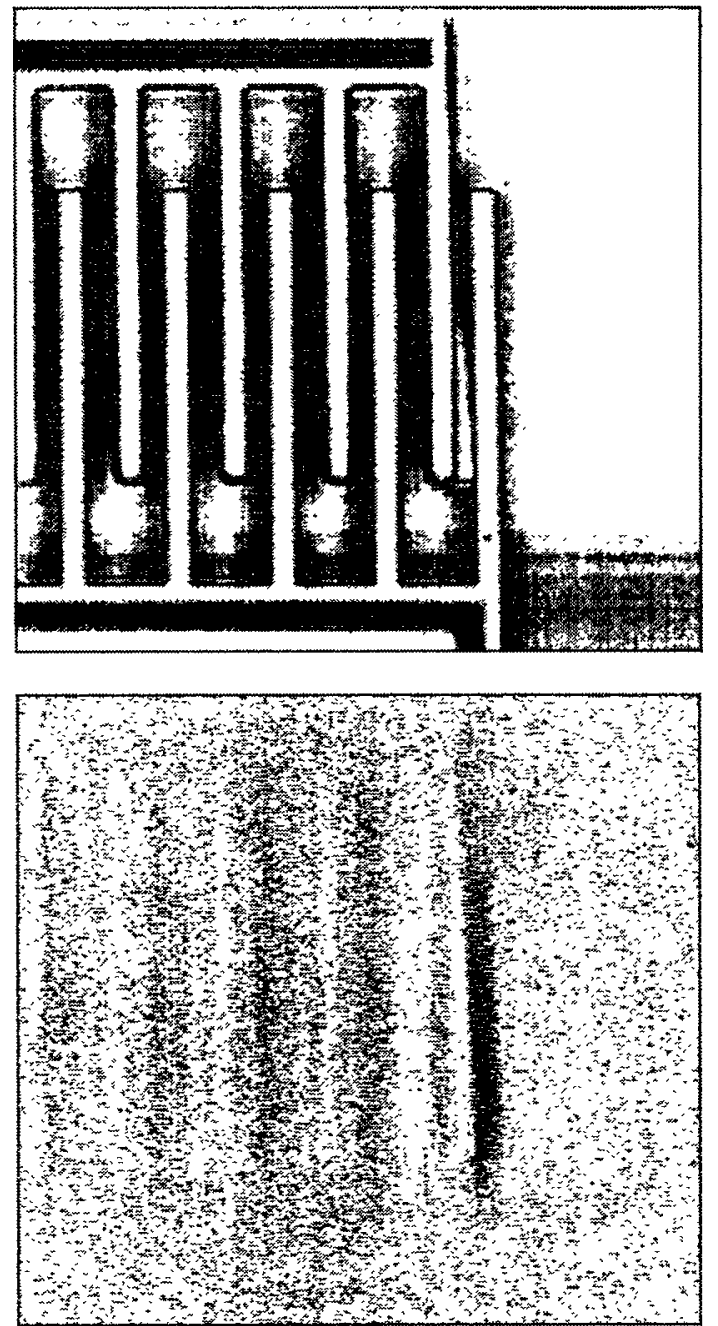

Figs. 13a and b. (a) Reflected-light and (b) TIVA image illustrating lateral contact of a bottom level moveable comb finger with a fixed comb finger.

using TIVA on conventional IC technologies. The absence of active photocurrent generation sites also allows the use of shorter wavelength stimulation lasers, resulting in improved image spatial resolution.

Backside analysis with infrared laser wavelengths as demonstrated on IC technologies [1] should also be possible on MEMS devices where front side access is prohibited due to fabrication of cover plates or other structures. TIVA should therefore continue to be a powerful tool for MEMS analysis in the future.

\section{Acknowledgements}

The authors would like to thank the Sandia microelectronics development laboratory staff for their processing and development efforts, Alex Pimentel for his FIB work, Chuck Hembree, Jerry Soden, and Dan Barton for discussions on ESD sensitivity and electrical shorting in MEMS. The 

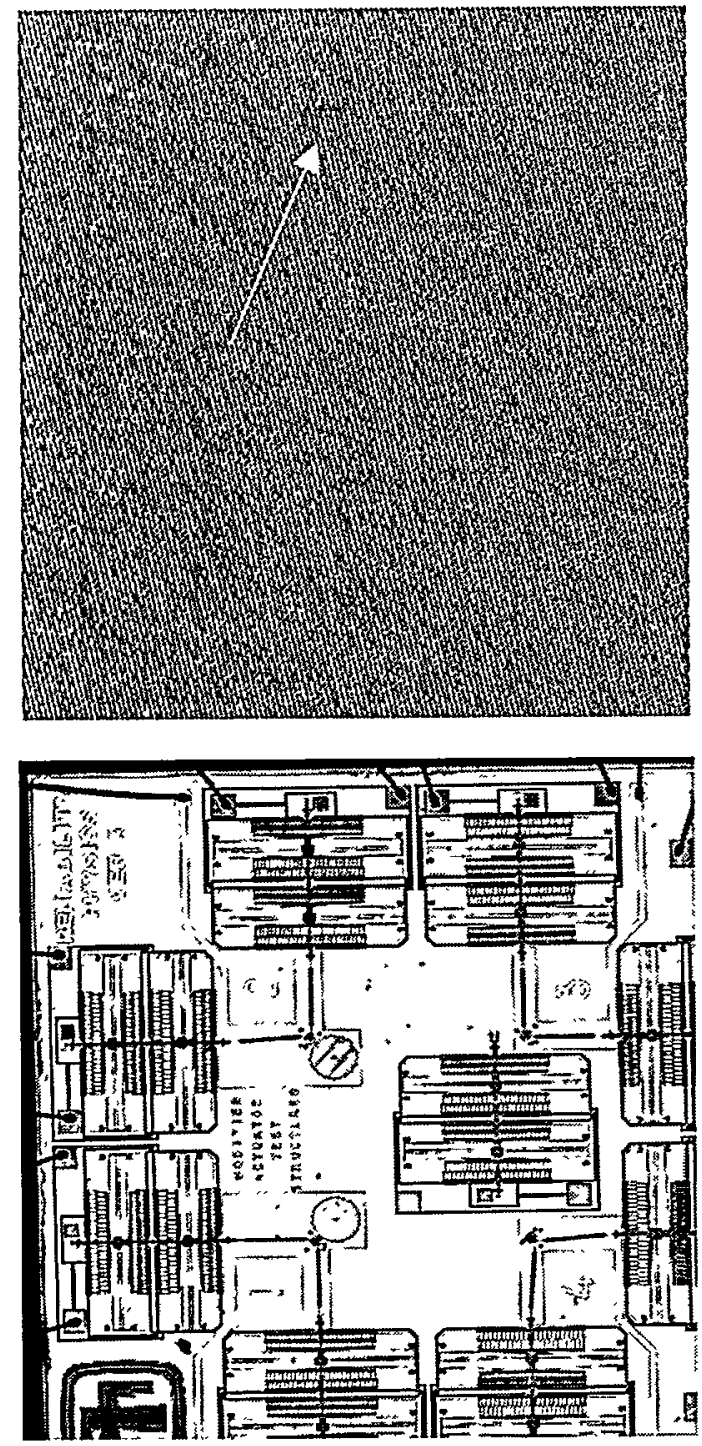

Figs. 14a and b. Low-magnification TIVA (a-top) and reflected-light (b-bottom) images and a particle short defect on a MEMS device. The field of view is the same for both images.

authors would also like to thank Charles Hembree, and Dan Barton for reviewing this paper.

Sandia National Laboratories is a multiprogram laboratory operated by the Sandia Corporation, a Lockheed Martin Company, for the United States Department of Energy under Contract DE-AC0494AL85000. For further information about MEMS technology at Sandia, please visit our website at: http:Ilwww.mems.sandia.gov.

\section{References}

1. E. I. Cole, Jr., P. Tangyunyong, D. A. Benson, and D. L. Barton, "TIVA and SEI developments for enhanced front and backside
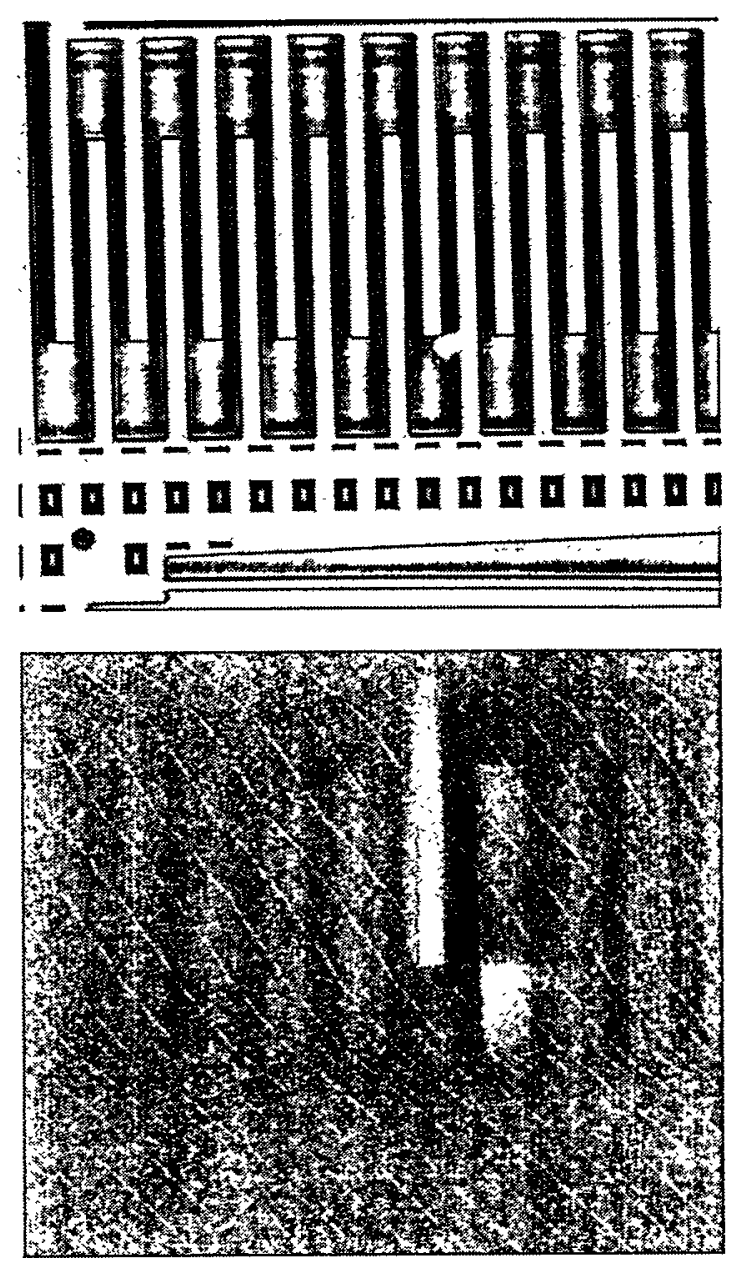

Figs. 15a and b. (a) Reflected-light and (b) TIVA image illustrating an electrical short caused by particle contamination between a moveable comb finger and a fixed comb finger.

interconnection failure analysis", ESREF, pp. 991-996 (1999).

2. M. P. de Boer, T. A. Michalske, "Accurate method for determining adhesion of cantilever beams," Journal of Applied Physics, Vol. 86, No. 2, pp. 817 - 827 (1999).

3. D. M. Tanner, J. A. Walraven, K. S. Helgesen, L. W. Irwin, F. Brown, N. F. Smith, and N. Masters, "MEMS reliability in shock environments", Proc. of IRPS, pp. 129-138 (2000).

4. J. A. Walraven, J. M. Soden, D. M. Tanner, P. Tangyunyong, E. I. Cole, Jr., R. E. Anderson, and L. W. Irwin, "Electrostatic Discharge/Electrical Overstress Susceptibility in MEMS: A New Failure Mode," to be published, Proc. SPIE (2000).

5. E. I. Cole, Jr. and R. E. Anderson, "Rapid localization of IC open conductors using charge-induced voltage alteration (CIVA)", IRPS, 288-298 (1992).

6. E. I. Cole, Jr., J. M. Soden, J. L. Rife, D. L. Barton, and C. L. Henderson. "Novel failure analysis techniques using photon probing in a 
scanning optical microscope", IRPS, 388-398 (1994).

7. R. A. Serway, Physics for Scientists \& Engineers with Modern Physics, pp. 605-606 $\left(2^{\text {nd }}\right.$ edn.), Saunders Publishing Co., NY, 1986.

8. K. Nikawa and S. Inoue, "Various contrasts identifiable from the backside of a chip by $1.3-\mu \mathrm{m}$ laser beam scanning \& current changing imaging", ISTFA, 387-392 (1996).

9. K. Nikawa and S. Inoue, "New capabilities of OBIRCH method for fault localization and defect detection", Proc. of Sixth Asian Test Symposium, 219-219 (1997).

10. Thermal Analysis System, TAS, Harvard Thermal, Inc., Harvard, MA 01451.

11. P. Tangyunyong, D. A. Benson, and E. I. Cole, Jr., "Thermal Modeling of TIVA Profiles of a Polysilicon-Metal Test Structure," to be published, J. of Vacuum Science and Technology B. 